\title{
ReSEARChArticle \\ Role of growth boosters on the yield of urd bean (Phaseolus mungo)
}

\author{
SANJEEV KUMAR, A.K. KATIYAR AND ANUJ KUMAR
}

\begin{abstract}
SUMMARY
The field experiments were conducted in Kharif 2013 and 2014 in Muzaffarnagar district of Uttar Pradesh on black gram (Urd) to assess the contribution of growth boosters commercially available in the market. For this purpose Aminos, Biozyme, Tracel and Planofix were sprayed on standing crop at 30 and 50 days after sowing. The seed of black gram was inoculated prior to sowing for all the treatments except control. Growth boosters were applied as alone and also their dual combinations. The data were recorded on plant growth characters at 40 and 70 days after sowing and yield attributing character were recorded at harvest. Among single applied growth boosters, Aminos (yield 8.90 and 9.32 q/ ha) contributed more as plant growth and yield attributing characters followed planofix (yield 8.66 and $9.11 \mathrm{q} /$ ha), tracel (yield 8.33 and $8.86 \mathrm{q} /$ ha) and biozyme (yield 8.10 and 7.86 q/ ha).Highest plant growth, yield attributing character and grain yield (yield 10.10 and $10.66 \mathrm{q} / \mathrm{ha}$ ) observed from dual application of aminos + planofix followed by aminos+ tracel (yield 9.90 and 10.35 q/ ha) aminos+ biozyme ( 9.86 and 10.26 q/ ha), biozyme+ planofix, planofix+ tracel and biozyme+ tracel from both the years of experiments.
\end{abstract}

Key Words : Black gram, Aminos, Biozyme, Tracel, Planofix, Rhizobium

How to cite this article : Kumar, Sanjeev, Katiyar, A.K. and Kumar, Anuj (2015). Role of growth boosters on the yield of urd bean (Phaseolus mungo). Internat. J. Plant Sci., 10 (1): 74-79.

Article chronicle : Received : 07.11.2014; Revised : 01.12.2014; Accepted : 18.12.2014

\section{MEMBERS OF THE RESEARCH FORUM}

Author to be contacted :

A.K. KATIYAR, Krishi Vigyan Kendra, Baghra, MUZAFFARNAGAR (U.P.)

INDIA

Email: katiyarakpbt@gmail,com

Address of the Co-authors:

SANJEEV KUMAR, Krishi Vigyan Kendra, Baghra, MUZAFFARNAGAR (U.P.) INDIA

ANUJ KUMAR, Department of Botany, C.C.R. P.G. College, MUZAFFARNAGAR (U.P.) INDIA 